\title{
Region-specific alterations of global protein expression in the remodelled rat myocardium
}

\author{
CHRISTIAN MELLE ${ }^{1 *}$, JUAN A. CAMACHO $^{2 *}$, RALF SURBER $^{3 *}$, STEFAN BETGE $^{3}$, \\ FERDINAND VON EGGELING ${ }^{1}$ and THOMAS ZIMMER ${ }^{2}$
}

\author{
${ }^{1}$ Core Unit Chip Application (CUCA), Institute of Human Genetics and Anthropology, ${ }^{2}$ Institute of Physiology II, \\ ${ }^{3}$ Department of Internal Medicine I, Friedrich Schiller University Jena, 07740 Jena, Germany
}

Received July 3, 2006; Accepted August 30, 2006

\begin{abstract}
We applied the novel ProteinChip ${ }^{\circledR}$ technology (SELDI-MS) to investigate and identify differentially regulated proteins upon myocardial remodelling in different heart regions. Tissue samples were isolated from the atria, the interventricular septum, and the right and left ventricles three months after surgically-induced myocardial infarction (MI) in rats. Corresponding protein extracts from control versus MI hearts were analysed on two different ProteinChip surfaces. In each of the functionally distinct cardiac regions, we obtained specific protein profile alterations upon myocardial remodelling. Most alterations were observed in the non-infarcted right ventricle, where down-regulation occurred more frequently than up-regulation of protein expression. Three of the differentially regulated proteins were identified: the metabolic enzyme triosephosphate isomerase (TIM), the cell signalling protein Raf-1 kinase inhibitory protein (RKIP), also known as phosphatidylethanolamine binding protein (PEBP), and the small heat shock protein $\alpha \mathrm{B}$ crystallin. These proteins showed a pronounced tissuedependent regulation. TIM was down-regulated only in the atrium and in the left ventricle, RKIP/PEBP was downregulated only in the right ventricle and in the interventricular septum, and $\alpha \mathrm{B}$-crystallin was up-regulated only in the right and in the left ventricle. A simple correlation of peak intensity changes using two of the identified peaks demonstrated the diagnostic potential of SELDI-MS. We conclude that this novel proteomic method is a powerful high-throughput tool for the fast detection of region-specific cardiac protein profiles in small biopsy samples, and that
\end{abstract}

Correspondence to: Dr Thomas Zimmer, Institute of Physiology II, Friedrich Schiller University, Kollegiengasse 9, 07743 Jena, Germany

E-mail: thomas.zimmer@mti.uni-jena.de

${ }^{*}$ Contributed equally

Key words: biomarker, cardiac remodelling, heart failure, myocytes, proteomics
SELDI-MS may become a useful complementary technique for the diagnosis and prognosis of cardiac diseases.

\section{Introduction}

Heart failure is a major public health problem. Although the survival rate after the onset of heart failure has improved during the last few years, the 5-year age-adjusted mortality rates are still very high (59\% in men and $45 \%$ in women) (1). One of the major causes of heart failure is ischemic heart disease (2), often accompanied by established myocardial infarction. Scarred myocardium does not contribute to contraction, leading to secondary volume overload, to pathological hypertrophy of the remaining left ventricle, and in later stages, to ventricular enlargement and pump failure. The term 'cardiac remodelling' comprises all of these phenomena (3). The clinical course after myocardial infarction is often accompanied by life threatening ventricular tachycardia and ventricular fibrillation, the most common cause of sudden cardiac death in the middle-aged and elderly population (4). In heart failure, several alterations at the cellular level have been reported, such as lysis of myofibrils, deformation of the sarcoplasmatic reticulum, and replacement of contractile myocytes by fibrous tissue $(5,6)$. Recently, extensive genomic and proteomic analyses have provided insight into the molecular mechanisms of cardiac remodelling, and many differentially regulated proteins have been reported (7-17).

Despite enormous effort and progress, specific pathophysiological pathways leading to the development and consolidation of a remodelled myocardium are still poorly understood, and genomic and proteomic methods are still far removed from being applied in the diagnosis and prognosis of heart failure. This is in part due to technical limitations. Genomic techniques such as mRNA differential display or microarray gene profiling are powerful regarding sensitivity and throughput, but there is often a poor correlation between transcript levels and the amount of the respective proteins, the molecular effectors in the cells $(18,19)$. On the other hand, proteomic techniques such as two-dimensional gel electrophoresis are time-consuming and require a starting sample amount in the micromolar range. This makes a highthroughput analysis of the cardiac proteome a laborious task.

A proteomic method that offers all the advantages of a chip-technology is the surface enhanced laser desorption/ 
ionization-mass spectrometry (SELDI-MS). This ProteinChip ${ }^{\circledR}$ technology uses chromatographic surfaces able to retain proteins depending on their physico-chemical properties, followed by direct analysis by time-of-flight mass spectrometry (TOF-MS) (20). Because proteins are retained on the surface, contaminants such as buffer salts or detergents can be easily washed away prior to MS analysis, thus eliminating the need for pre-separation techniques. The extremely low sample requirements of this technique are ideal for small biopsy samples or low cell number tissue extracts (21). When specific changes between the protein profiles of the different groups of samples are found, the proteins can be isolated by different chromatographic or electrophoretic techniques, digested by enzymatic cleavage and finally identified by peptide mapping. The predominant majority of SELDI-MS studies were carried out using cancer tissues and biological fluids, and several novel biomarkers have been identified so far (22).

In the present study, we applied SELDI-MS technology to analyse alterations of protein profiles upon myocardial remodelling in a rat infarct model. We compared protein profiles of small tissue samples from atria, the interventricular septum, and the left and the right ventricle. Our data demonstrate that these different heart regions respond specifically at the molecular level to the infarct, with most changes occurring in the right but not in the hypertrophied left ventricle. Three of the differentially regulated proteins were identified by two-dimensional gel electrophoresis (2-DE) and peptide mapping experiments. Implications of the SELDI-MS technique for basic research and for the clinical diagnosis and prognosis of heart failure are discussed.

\section{Materials and methods}

Experimental myocardial infarction (MI) in rats. Female Lewis rats (3 months of age, weight 180-210 g) were used in all experiments. Myocardial infarction was induced as previously described (23). Briefly, after an intraperitoneal injection of $30 \mathrm{mg} / \mathrm{kg}$ pentobarbital, a tracheotomy was performed and general anaesthesia was maintained with artificial ventilation $\left(\mathrm{O}_{2}-\mathrm{N}_{2} \mathrm{O}\right.$-isoflurane). A left lateral thoracotomy was performed, the pericardium was opened, and the left anterior descending artery was ligated 1-2 mm distal to its origin from the ascending aorta. After three months, rats were anaesthetised by inhalation of a mixture of $50 \% \mathrm{O}_{2}$ and $50 \% \mathrm{CO}_{2}$ and sacrificed by cervical dislocation. The hearts were excised, rinsed in saline to remove excess blood, and the scarred tissue and great vessels were removed. Specimens were dissected into atria (A), the right ventricular free wall $(\mathrm{RV})$, interventricular septum $(\mathrm{S})$, and the remaining posterior/inferior part of the left ventricle (LV). To analyse cell length and thickness, ventricular cardiomyocytes of MI and control rats were obtained by enzymatic dissection with collagenase, as previously described (24), and the respective cell parameters were obtained with a laser scanning microscope (LSM 510, Zeiss, Germany) and the implemented software. The investigation conforms with the Guide for the Care and Use of Laboratory Animals published by the US National Institute of Health (NIH publication no. 85-23, revised 1985).
Cell lysate preparation. Heart tissues were homogenised mechanically with an Ultra-Turrax T8 homogenizer (IKA Labortechnik, Staufen, Germany) in ice-cold lysis buffer (1 ml per $20 \mathrm{mg}$ tissue) containing $2 \mathrm{mM} \mathrm{MgCl}_{2}, 3 \mathrm{mM} 2-\beta-$ mercaptoethanol, $0.1 \mathrm{mM}$ phenylmethanesulfonyl fluoride (PMSF), protease inhibitor cocktail (1 tablet of Complete ${ }^{\mathrm{TM}}$ Mini per $10 \mathrm{ml}$ buffer; Roche Diagnostics GmbH, Mannheim, Germany), 0.1\% 3-[(3-cholamidopropyl)dimethylammonio]-1-propane sulfonate (CHAPS), and $0.1 \mathrm{M}$ phosphate buffer ( $\mathrm{pH} 7.5$ ). Cell lysates were vortexed for $2 \mathrm{~min}$ at $4{ }^{\circ} \mathrm{C}$, stored on ice for $30 \mathrm{~min}$, and finally centrifuged for $20 \mathrm{~min}$ at $14,000 \mathrm{rpm}\left(4^{\circ} \mathrm{C}\right)$. The supernatant was immediately analysed. The protein concentration was determined (BioRad protein kit) to allow for a comparable sample load onto the chip surfaces. Protein concentrations of lysates were adjusted to nearly $1.5 \mathrm{mg} / \mathrm{ml}$.

SELDI-MS ProteinChip binding and analysis. The protein lysates were analysed on an anionic (SAX) and cationic exchanger array (WCX, Ciphergen Biosystems Inc., Fremont, CA) as described elsewhere (25). Briefly, spots on the arrays were equilibrated, and the ProteinChip array was incubated in a humidity chamber for $90 \mathrm{~min}$ at room temperature after application of the protein sample. Afterward, spots were washed and air dried. After application of $2 \times 0.5 \mu 1$ saturated sinapinic acid (Sigma) dissolved in $50 \%$ acetonitrile (Sigma) containing $0.5 \%$ trifluoroacetic acid (Sigma), mass analysis was performed in a ProteinChip reader (PBS-II, Ciphergen Biosystems), according to an automated data collection protocol. Normalization of all spectra was performed using total ion current. Cluster analysis of the detected signals and the determination of respective $\mathrm{p}$ values were carried out with the Biomarker Wizard program (version 3.0, Ciphergen Biosystems Inc.). For $\mathrm{p}$ value calculation, spectra with at least 10 signals in the range between $2 \mathrm{kDa}$ and $20 \mathrm{kDa}$ exhibiting a signal-to-noise ratio of at least 5 were selected and analysed with the Mann-Whitney U test for non-parametric data sets.

Two-dimensional gel electrophoresis and in-gel digestion. Two-dimensional gel electrophoresis and in-gel digestion were performed as described elsewhere (25). In brief, isoelectric focusing (IEF) was carried out on a Multiphor II (Amersham) using 17-cm IPG strips in a pI range of 3-10. Vertical SDSPAGE was performed in a cooled PROTEAN II xi Cell (BioRad) using $12 \%$ acrylamide gels. The gels were stained with Simply Blue safe stain (Enhanced Coomassie, Invitrogen). Excised gel pieces were destained and dried. After rehydration and digestion with $10 \mu \mathrm{l}$ of a trypsin solution $(0.02 \mu \mathrm{g} / \mu \mathrm{l}$; Roche Diagnostics $\mathrm{GmbH}$ ) at $37^{\circ} \mathrm{C}$ for $7 \mathrm{~h}$, supernatants were applied directly on a NP20 ProteinChip array (Ciphergen Biosystems Inc.). After addition of the matrix (CHCA; Ciphergen Biosystems Inc.), peptide fragment masses were analysed using the ProteinChip reader. The spectra for the peptide mapping experiments were externally calibrated using five standard proteins including Arg8-vasopressin (1082.2 Da), somatostatin (1637.9 Da), dynorphin (2147.5 Da), ACTH (2933.5 Da), and insulin B-chain (3495.94 Da). Proteins were identified using the fragment masses generated through trypsin digestion by searching in a database (http://129.85.19.192/profound_bin/WebProFound.exe). 
Table I. Overall alterations in protein expression upon myocardial remodelling analysed by SELDI-MS. ${ }^{\mathrm{a}}$

\begin{tabular}{|c|c|c|c|c|c|}
\hline \multirow[t]{2}{*}{ Heart region } & \multirow[t]{2}{*}{ Chip surface } & \multirow{2}{*}{$\begin{array}{l}\text { No. of animals } \\
\text { control/infarct }\end{array}$} & \multirow[t]{2}{*}{ No. of signals } & \multicolumn{2}{|c|}{ Differentially expressed proteins } \\
\hline & & & & up-regulated & down-regulated \\
\hline \multirow[t]{4}{*}{ RV } & SAX low & $13 / 12$ & 56 & 1 & 18 \\
\hline & middle & $11 / 11$ & 39 & 1 & 2 \\
\hline & WCX low & $12 / 10$ & 71 & 1 & 6 \\
\hline & middle & $13 / 9$ & 35 & 0 & 0 \\
\hline \multirow[t]{4}{*}{ LV } & SAX low & $12 / 10$ & 56 & 0 & 3 \\
\hline & middle & $13 / 11$ & 35 & 1 & 1 \\
\hline & WCX low & $13 / 12$ & 74 & 0 & 0 \\
\hline & middle & $12 / 11$ & 44 & 0 & 2 \\
\hline \multirow[t]{4}{*}{$\mathrm{S}$} & SAX low & $11 / 12$ & 49 & 0 & 1 \\
\hline & middle & $10 / 11$ & 33 & 0 & 1 \\
\hline & WCX low & $12 / 11$ & 70 & 0 & 0 \\
\hline & middle & $10 / 10$ & 14 & 0 & 0 \\
\hline \multirow[t]{4}{*}{$\mathrm{A}$} & SAX low & $11 / 12$ & 65 & 2 & 0 \\
\hline & middle & $12 / 12$ & 16 & 1 & 1 \\
\hline & WCX low & $13 / 12$ & 75 & 0 & 1 \\
\hline & middle & $12 / 11$ & 39 & 0 & 2 \\
\hline
\end{tabular}

aProtein profiles were analysed using an anion exchange protein chip (SAX) and a cation exchange protein chip (WCX) between 2.5 and $20 \mathrm{kDa}$ (low), and beween 20 and $80 \mathrm{kDa}$ (middle). RV, right ventricle; LV, left ventricle; S, septum; and A, atrium.

\section{Results}

Characterisation of MI rats. The operation resulted in large anterior myocardial infarctions in $\sim 80 \%$ of the operated animals. Atria (A), the right ventricle (RV) and the noninfarcted part of the left ventricle (LV) were hypertrophied three months after the infarct. Large scars were present in the anterior and lateral wall of the left ventricle. The hearts of the MI rats were markedly enlarged with a nearly doubled heart to body weight ratio $(9.5 \pm 0.5 \mathrm{~g} / \mathrm{kg}$ for MI rats versus $5.2 \pm 0.2$ $\mathrm{g} / \mathrm{kg}$ for controls), similarly as previously described for this model $(26,27)$. Analysing morphological changes of remodelled cardiomyocytes by laser scanning microscopy, we found a significant increase in cell length and thickness by $\sim 50 \%$. The cell length increased from $118.6 \pm 1.9 \mu \mathrm{m}$ to $189.8 \pm 4.6 \mu \mathrm{m}$, and the thickness increased from $20.7 \pm 0.7 \mu \mathrm{m}$ to $30.1 \pm 1.3 \mu \mathrm{m}(\mathrm{p}<0.05)$. In conclusion, these data indicate that the infarct was successfully induced and that MI rats were characterised by a remodelled myocardium three months after the operation.

Region-specific expression profiles upon myocardial remodelling. Control and remodelled MI hearts were dissected into atria (A), the right ventricular free wall (RV), interventricular septum (S), and the posterior/inferior part of the left ventricle (LV) omitting any scarred tissue. Proteins of these regions were analysed using two different chip surfaces, an anionic (SAX) and a cationic exchanger array (WCX). Both chips revealed several differentially expressed proteins in a molecular mass range between 3 and $56 \mathrm{kDa}$ (Tables I

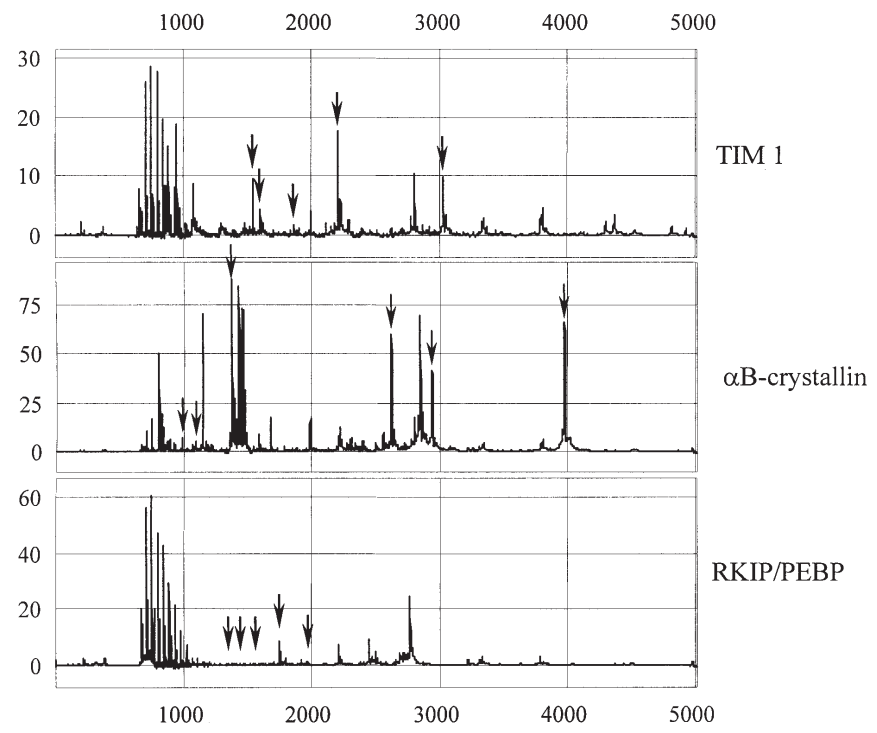

Figure 1. Identification of TIM, $\alpha$ B-crystallin, and RKIP/PEBP by trypsindigested peptide mass fingerprints. Excised gel pieces were subjected to in-gel digestion, and fragments were analysed by SELDI-MS. Peptide fingerprint mapping was used for database queries.

and II). To note, protein down-regulation occurred more frequently than protein up-regulation. Furthermore, we noticed striking region-specific changes. With both chip surfaces, we found that the right ventricle was most affected by the infarct (Table 1). Among all protein peaks detected on 
Table II. Molecular mass of proteins differentially expressed in the four different rat heart regions, three months after myocardial infarction.

\begin{tabular}{|c|c|c|c|c|c|}
\hline \multirow[t]{2}{*}{ Region } & \multicolumn{2}{|c|}{ Molecular mass (kDa) } & \multirow[t]{2}{*}{$\mathrm{p}$ value } & \multirow[t]{2}{*}{ Chip surface } & \multirow[t]{2}{*}{ Corresponding to } \\
\hline & up-regulated & down-regulated & & & \\
\hline \multirow[t]{26}{*}{ RV } & 3.195 & & 0.0255 & WCX & \\
\hline & 16.785 & & 0.0166 & SAX & \\
\hline & 20.135 & & 0.0385 & SAX & $\alpha \mathrm{B}-$ crystallin \\
\hline & & 5.492 & 0.0295 & SAX & \\
\hline & & 5.642 & 0.0123 & SAX/WCX & \\
\hline & & 5.698 & 0.0295 & SAX & \\
\hline & & 5.909 & 0.0013 & SAX & \\
\hline & & 6.297 & 0.0441 & SAX & \\
\hline & & 6.653 & 0.0002 & SAX/WCX & \\
\hline & & 6.871 & 0.0009 & SAX & \\
\hline & & 7.334 & 0.0047 & SAX & \\
\hline & & 8.126 & 0.0039 & SAX/WCX & \\
\hline & & 8.370 & 0.0063 & WCX & \\
\hline & & 8.384 & 0.0013 & SAX & \\
\hline & & 8.461 & 0.0008 & SAX & \\
\hline & & 8.930 & 0.0193 & SAX & \\
\hline & & 9.720 & 0.0039 & SAX & \\
\hline & & 9.981 & 0.0255 & WCX & \\
\hline & & 10.365 & 0.0223 & SAX & \\
\hline & & 10.778 & 0.0055 & SAX & \\
\hline & & 10.800 & 0.0349 & WCX & \\
\hline & & 11.371 & 0.0257 & SAX & \\
\hline & & 11.837 & 0.0090 & SAX & \\
\hline & & 12.436 & 0.0065 & SAX & \\
\hline & & 20.996 & 0.0281 & SAX & RKIP/PEBP \\
\hline & & 55.318 & 0.0385 & SAX & \\
\hline \multirow[t]{7}{*}{ LV } & 20.131 & & 0.0081 & SAX & $\alpha \mathrm{B}-$ crystallin \\
\hline & & 6.864 & 0.0349 & SAX & \\
\hline & & 9.472 & 0.0039 & SAX & \\
\hline & & 11.831 & 0.0016 & SAX & \\
\hline & & 27.335 & 0.0130 & WCX & TIM \\
\hline & & 28.049 & 0.0243 & WCX & \\
\hline & & 55.360 & 0.0363 & SAX & \\
\hline \multirow[t]{2}{*}{$S$} & & 10.776 & 0.0243 & SAX & \\
\hline & & 20.999 & 0.0278 & SAX & RKIP/PEBP \\
\hline \multirow[t]{7}{*}{ A } & 7.242 & & 0.0179 & SAX & \\
\hline & 9.123 & & 0.0066 & SAX & \\
\hline & 42.817 & & 0.0326 & SAX & \\
\hline & & 5.304 & 0.0223 & WCX & \\
\hline & & 22.058 & 0.0496 & SAX & \\
\hline & & 27.336 & 0.0488 & WCX & TIM \\
\hline & & 27.997 & 0.0488 & WCX & \\
\hline
\end{tabular}

RKIP/PEBP, Raf-1 kinase inhibitory protein/phosphatidylethanolamine binding protein; TIM, triosephosphate isomerase 1.

the SAX chip (low molecular weight range), 33.9\% showed a significantly altered expression level. In the other three heart regions, the respective fraction of differentially regulated proteins was clearly smaller (2-6\%). In conclusion, the infarction induced dramatic alterations of protein expression in the non-infarcted right ventricle whereas the left ventricular response was much less pronounced and of a similar intensity as observed in the atria.
To identify some of the differentially regulated proteins and thus to gain insight into the molecular mechanism of the cardiac remodelling process in the different heart regions, respective protein extracts were separated by 2-DE. Protein spots were excised and subjected to in-gel digestion with trypsin. Finally, proteins were identified by analysing respectively generated fragment masses on the ProteinChip reader. Among 40 unambiguously identified proteins, three 
Table III. Trypsin-digested peptide mass fingerprints of three differentially regulated proteins.

\begin{tabular}{lccc}
\hline No. & Masses matched $(\mathrm{kDa})$ & Accession & Protein \\
\hline 1 & $1540.0 / 1603.4 / 1867.8 / 2207.2 / 3031.2$ & P48500 & TIM \\
2 & $1350.4 / 1438.3 / 1560.6 / 1742.0 / 1963.0$ & P31044 & RKIP/PEBP \\
3 & $985.7 / 1088.5 / 1374.9 / 2624.6 / 2943.9 / 3978.7$ & P23928 & $\alpha B-c r y s t a l l i n$ \\
\hline
\end{tabular}

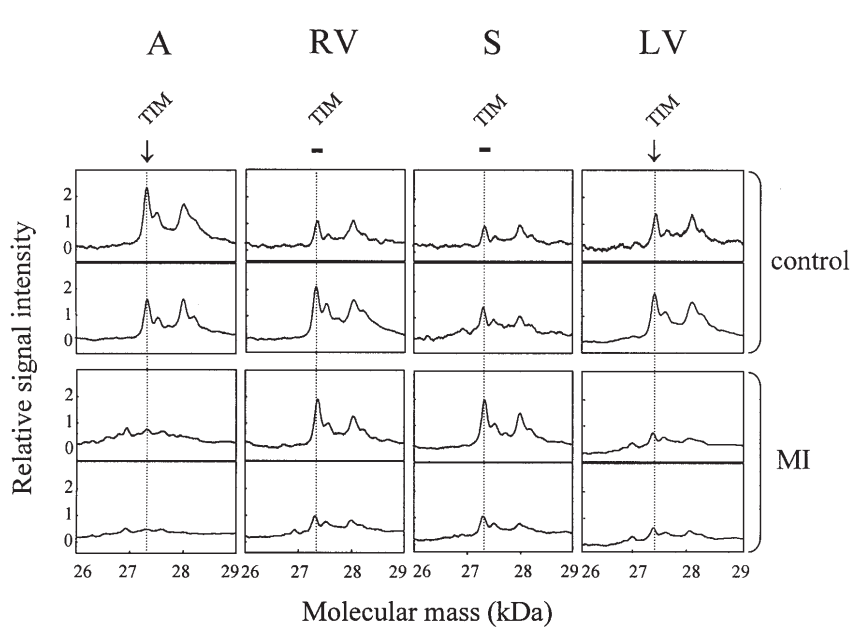

Figure 2. Differential regulation of triosephosphate isomerase 1 (TIM) in the four different heart regions. The figure shows representative SELDI-MS profiles from WXC-chip surface captured proteins between 26 and $29 \mathrm{kDa}$. Down-regulation of TIM (dotted line) in the remodelled atria and in the left ventricle of $\mathrm{MI}$ rats is indicated by an arrow. A, atria; RV, right ventricle; $\mathrm{S}$, septum; LV, left ventricle.

proteins, TIM (EC. 5.3.1.1), $\alpha \mathrm{B}$-crystallin, and RKIP/PEBP corresponded well to significantly differential signals detected in prior ProteinChip analysis (Fig. 1, Tables II and III).

The enzyme triosephosphate isomerase (TIM) appeared to be down-regulated only in the atria and in the left ventricle $(p<0.05$, see arrows in Fig. 2). In the right ventricle as well as in the interventricular septum, this enzyme was not differentially regulated compared to the corresponding regions of the control hearts $(\mathrm{p}>0.2)$. The heat shock protein $\alpha \mathrm{B}$-crystallin was significantly up-regulated in the working myocardium of both ventricles $(\mathrm{p}<0.05$, Fig. 3$)$. In the interventricular septum and in the atria, up-regulation was less pronounced and did not reach statistical significance at $\mathrm{p}<0.05$ ( $\mathrm{p}=0.11$ and $\mathrm{p}=0.06$, respectively). Expression of the cell signalling protein RKIP (or PEBP) was down-regulated only in ventricular tissues $(\mathrm{p}=0.003$ in $\mathrm{RV}, \mathrm{p}=0.028$ in $\mathrm{S}$ and $\mathrm{p}=0.06$ in LV), but clearly not differentially regulated in the atria ( $\mathrm{p}=0.8$, Fig. 3 ). These results show that cardiac adaptation upon myocardial infarction requires expression profile changes that are strictly specific for each of the different heart regions. Discrimination of normal and remodelled heart tissues by SELDI-MS. By evaluating only one relative value for the expression level of a given regulated protein such as TIM or $\alpha \mathrm{B}$-crystallin, an assignment of 'normal' or 'remodelled' of a single biopsy sample from the heart is quite complicated.
There is a considerable natural variance in protein expression in normal hearts, and more importantly, control samples of remodelled hearts are usually not available for a direct comparison. We tried to classify the rat ventricular heart samples as 'normal' or 'remodelled' simply by evaluating the ratio of the peak intensities of an up-regulated versus a down-regulated protein. Fig. 4 shows the expression patterns of all left ventricular samples of control and remodelled MI rats on the SAX chip between 19.0 and $22.0 \mathrm{kDa}$, comprising peaks for $\alpha \mathrm{B}$-crystallin at $20.13 \mathrm{kDa}$ and for PEBP/RKIP at $\sim 20.99 \mathrm{kDa}$. When comparing the ratio of both peaks for control and the MI hearts, we found that in all 11 samples from the MI rats, the signal at $\sim 20.13 \mathrm{kDa}$ was larger than the signal at $20.99 \mathrm{kDa}$ (Fig. 4, right). In 9 out of 13 control samples, both peaks were either of similar intensity or the respective ratio was inversed with the larger signal at $20.99 \mathrm{kDa}$ (Fig. 4, left). Thus, 20 out of 24 samples from the left ventricle $(\sim 83.3 \%)$ were correctly diagnosed when assuming that the peak ratio at $20.13: 20.99 \mathrm{kDa}$ is $>1$ in MI and $\leq 1$ in normal hearts. Only four control hearts (* in Fig. 4), but no MI heart were incorrectly classified. As shown in Fig. 5, similar results were obtained when analysing the corresponding profile of the right ventricular samples: 17 out of 22 samples were diagnosed correctly $(\sim 77.3 \%)$ with only 1 out of $11 \mathrm{MI}$ hearts classified as 'normal' (* in Fig. 5, right).

\section{Discussion}

In the present study, we applied the ProteinChip ${ }^{\circledR}$ technology (SELDI-MS) to investigate differentially regulated proteins upon myocardial remodelling in a rat infarct model. To the best of our knowledge, this represents the first report on the application of this novel high-throughput technique for the analysis of proteins differentially regulated in remodelled versus normal hearts. In each of the functionally distinct cardiac regions, we obtained specific protein profile alterations (Table II, Figs. 2 and 3). Noticeably, most alterations were found in the non-infarcted right ventricle. Down-regulation occurred more frequently than up-regulation of protein expression (Tables I and II). First attempts to identify differentially regulated proteins revealed the identity of three of the affected proteins (Table III, Fig. 1).

SELDI-MS, a powerful method to identify differentially regulated proteins in different heart regions and cell types. Despite some technical limitations associated with the SELDI-MS approach (see below), this method offers several advantages over other proteomic techniques. The straightforward and fast sample preparation procedure in combination with the automated high-throughput processing of the chip 


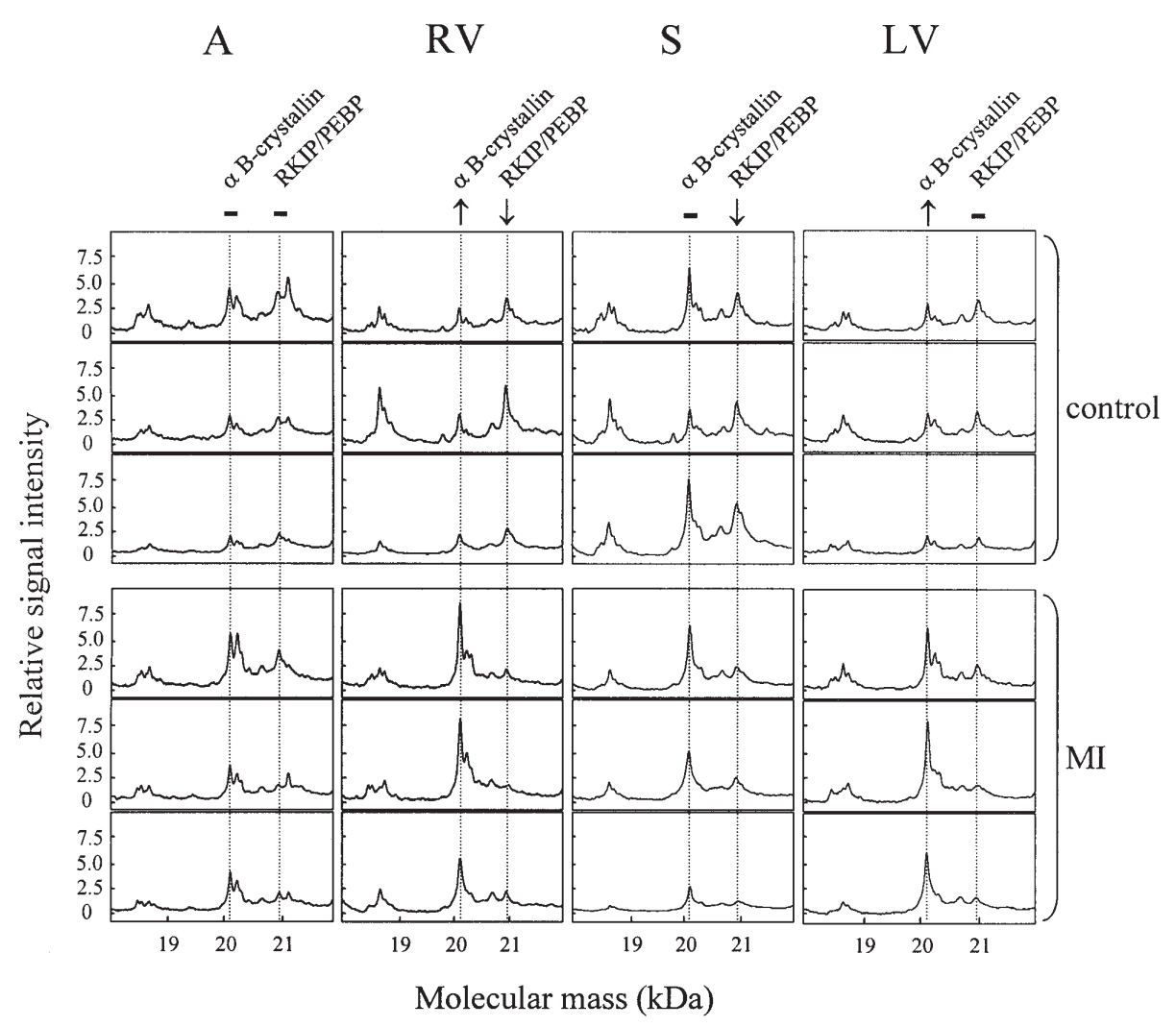

Figure 3. Differential regulation of $\alpha \mathrm{B}$-crystallin and Raf-1 kinase inhibitory protein/phosphatidylethanolamine-binding protein (RKIP/PEBP) in four different heart regions. Representative SELDI-MS profiles from SAX-chip surface captured proteins are shown between 18 and $22 \mathrm{kDa}$. Signals corresponding to $\alpha \mathrm{B}$-crystallin and RKIP/PEBP at 20.13 and $20.99 \mathrm{kDa}$, respectively, are marked by the dotted line. Up- or down-regulation in remodelled heart regions is indicated by the respective arrows. A, atria; $\mathrm{RV}$, right ventricle; $\mathrm{S}$, septum; $\mathrm{LV}$, left ventricle.

spots allow the handling of a large sample number. Moreover, SELDI-MS technology is characterised by an extreme low sample requirement in the nanomolar range (21). For the analysis of complicated organs such as the heart, such a fast and sensitive proteomic method is particularly important. The heart consists of a variety of functionally different regions and cell types that may specifically respond to the requirements associated with the cardiac remodelling process. As shown in the present study, the four different heart regions developed specific protein patterns (Table II, Figs. 2 and 3), e.g., triosephosphate isomerase (TIM), a homodimeric enzyme catalysing the interconversion of D-glyceraldehyde-3phosphate and dihydroxyacetone phosphate, was downregulated only in the left ventricle and in the atria, but not in the right ventricle or in the interventricular septum. At the same time, cell signalling protein RKIP/PEBP was downregulated only in ventricular tissues, but not in the atria. These data suggest that, upon cardiac remodelling, both metabolic and cell signalling pathways undergo a distinct adaptation in the different heart regions. In the case of $\alpha \mathrm{B}$-crystallin, the most abundant small heat shock protein in the heart, we also found a region-specific alteration of expression. We detected a clear up-regulation in the ventricular myocardium, whereas the moderate increase in $\alpha \mathrm{B}$-crystallin expression in the atria and in the interventricular septum did not reach statistical significance at $\mathrm{p}<0.05$. This finding indicates that, compared to the septum and atria, a particularly strong stress response is required to maintain ventricular function.
We suggest that for a better understanding of the complexity of the cardiac remodelling process including functional implications of the discovered changes in protein expression, it will be challenging and vital to identify specific protein profiles and biomarkers in the different heart cells and tissues, including epicardial and endocardial cells, sinus node cells, Purkinje fibers as well as fibroblasts and blood vessels. Since SELDI-MS allows the analysis of respective protein profiles using few cells, and in combination with dissection techniques such as laser capture microdissection, cell-type specific investigations of cardiac remodelling hold much promise.

Role of cell signalling protein RKIP/PEBP in heart failure. In contrast to TIM and $\alpha B$-crystallin, the differential regulation of RKIP/PEBP upon myocardial remodelling has not been observed previously by other proteomic methods. Interestingly, the observed pathophysiological down-regulation of this cell signalling protein can explain the pronounced reduction of positive inotropic effects of $\beta$-adrenergic receptor agonists in the failing heart, and complements previous in vitro studies $(28,29)$. Upon protein kinase C (PKC)-dependent phosphorylation, RKIP/PEPB dissociates from Raf-1 and blocks G-protein-coupled-receptor kinase 2 (GRK-2), thereby preventing the inactivation and internalisation of activated G-protein-coupled receptors (GPCR, 29). Consequently, down-regulation of RKIP/PEBP results in restrained Badrenergic signalling, as shown recently by in vitro gene 
control

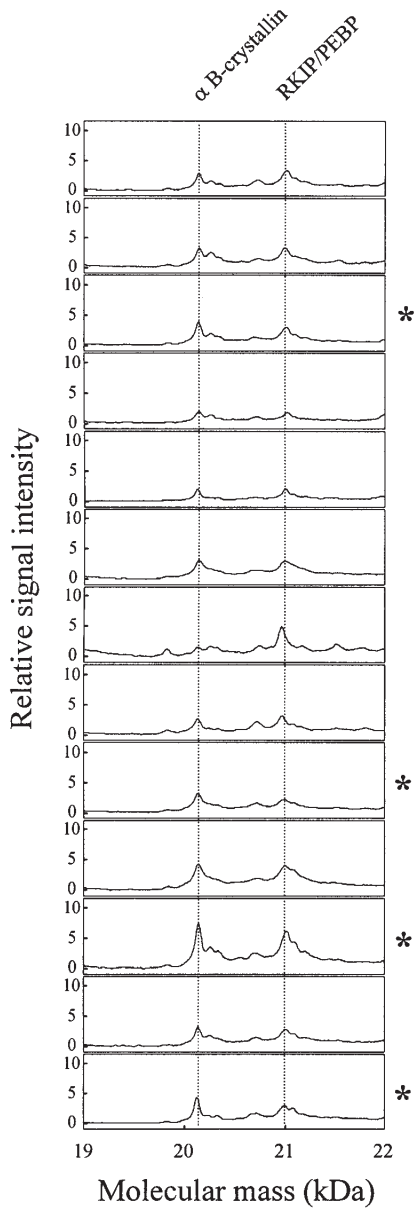

$\mathrm{MI}$

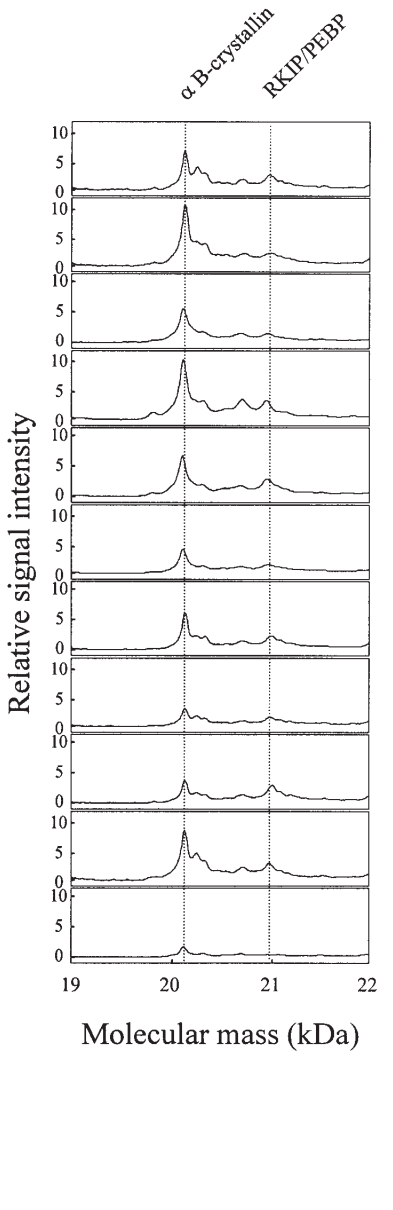

Figure 4. Consecutive SELDI-MS profiles of the left ventricular proteins obtained by the SAX-chip surface (middle range). Upon up-regulation of $\alpha B$-crystallin and down-regulation of RKIP/PEBP in the remodelled left ventricle of MI rats, the signal at $20.13 \mathrm{kDa}$ ( $\alpha \mathrm{B}$-crystallin) became larger than the peak at $20.99 \mathrm{kDa}$ (RKIP/PEBP) in all 11 investigated samples. In contrast, the peak ratio at $20.13: 20.99 \mathrm{kDa}$ was $\leq 1$ in 9 out of the 13 investigated control hearts. In the remaining 4 control hearts $(*)$, the peak at $20.13 \mathrm{kDa}$ was only slightly larger compared to the signal at $20.99 \mathrm{kDa}$. Nearly $83 \%$ of all investigated left ventricular samples were correctly diagnosed when assuming that the peak ratio at $20.13: 20.99 \mathrm{kDa}$ is $>1$ in MI and $\leq 1$ in normal hearts

silencing experiments (29). This effect is intensified by downregulation of $ß 1$-receptor expression as previously reported (28). At the same time, the resulting disinhibition of the mitogen-activated protein kinase (MAPK) cascade may activate the transcription of the respective genes. Whether or not down-regulation of RKIP/PEBP can be linked to the upregulated proteins reported in Table II or in other genomic/ proteomic studies remains to be investigated.

Strong alteration of protein expression in the non-infarcted right ventricle. The number of differentially expressed proteins was much higher in the right than in the left ventricle (Tables I and II), suggesting that long-term adaptation mechanisms upon cardiac infarction mainly concern the right ventricular chamber. Larger volumes in the left ventricle combined with its global dysfunction (26) could result via an increased hemodynamic pressure in the pulmonary circulation
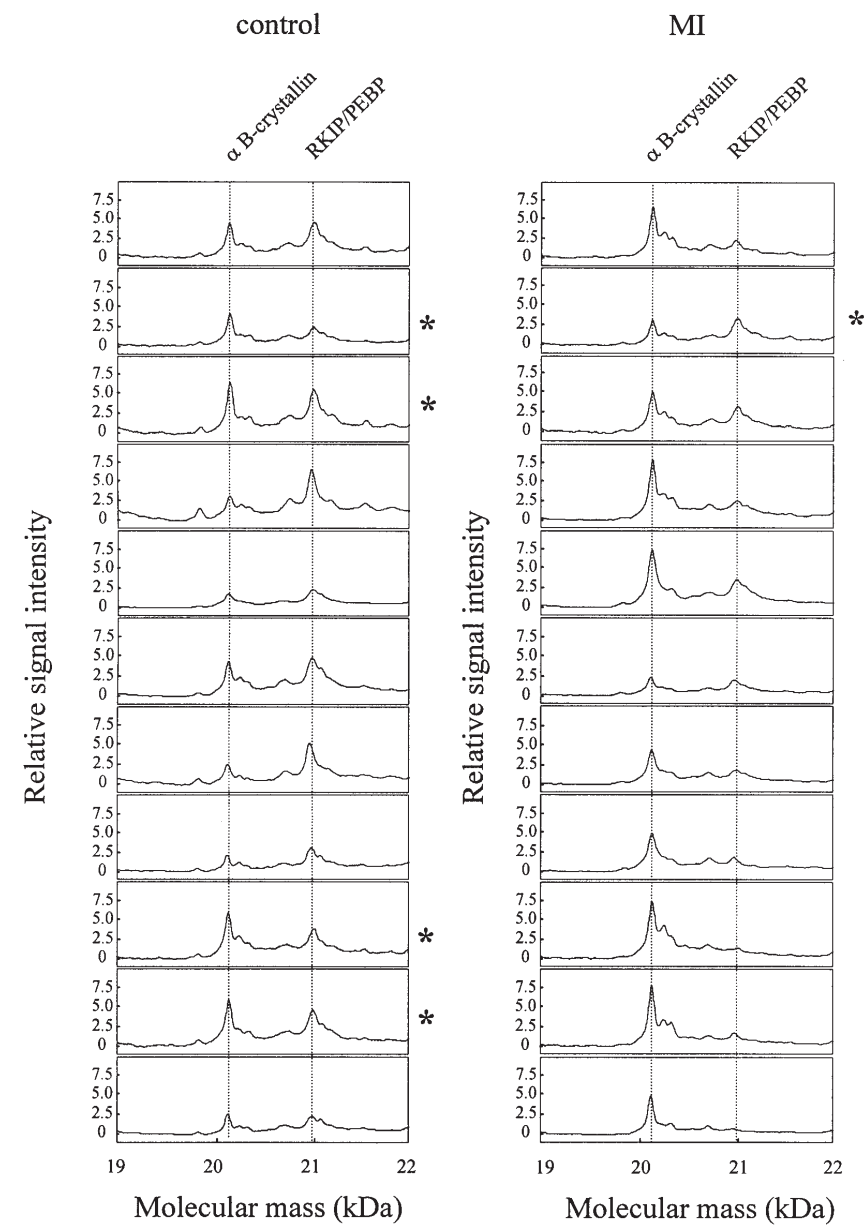

Figure 5. Consecutive SELDI-MS profiles of the right ventricular proteins obtained by the SAX-chip surface (middle range). Due to the simultaneous up- and down-regulation of $\alpha \mathrm{B}$-crystallin and RKIP/PEBP, respectively, the signal at $20.13 \mathrm{kDa}(\alpha \mathrm{B}$-crystallin) became larger than the peak at $20.99 \mathrm{kDa}$ (RKIP/PEBP) in 10 out of 11 MI samples, similarly as observed for the left ventricular tissue. Again, nearly $77 \%$ of all right ventricular samples were correctly diagnosed when assuming that the peak ratio at $20.13: 20.99 \mathrm{kDa}$ is $>1$ in $\mathrm{MI}$ and $\leq 1$ in normal hearts.

system to an increased afterload in the right ventricle, thus creating a strong hypertrophic stimulus. Supporting this view, Anand et al (26) found for the same animal model that the increase in myocyte length and width in MI hearts was more pronounced in the case of right ventricular myocytes compared to cells from the left ventricle. Our protein data are also supported by a previous study using DNA microarrays (13). These authors compared gene expression in the left and right ventricle of MI rats and found a stronger right ventricular response. They also noticed that down-regulation of gene expression occurred more frequently than a respective up-regulation. A preferred down-regulation of protein expression in ventricular tissues was also reported in several previous proteomic studies on dilated cardiomyopathy or pacing-induced canine heart failure (reviewed in refs. 12 and 14). Although the physiological meaning behind this phenomenon remains to be elucidated, collectively these data suggest that diseased cardiomyocytes enhance important cellular processes such as stress response at the expense of minimising other less important pathways. 
Limitations of SELDI-MS for studies on cardiac protein profiles. At the present state of the SELDI-MS technology, some special features limit the application of this method for the discovery and identification of differentially regulated proteins in the diseased heart (22), similar to other analytical proteomic techniques. First, a complete coverage of the proteome is currently impossible. The range below $30 \mathrm{kDa}$ is particularly well resolved, but the signal number in the higher molecular weight range is strikingly lower. Available chip surfaces obviously do not allow for the appropriate binding/separation of all proteins in the heart extract. Second, large signals for abundant proteins may interfere with the identification of less abundant proteins of similar molecular weight. Third, low intensity changes are probably not often recognised despite their possible physiological importance. Although all experimental steps such as animal husbandry, isolation of the hearts and protein extracts were performed comparably, we still observed a protein profile variability among both control and MI rats. In the present study, we used between 9 and 13 hearts for each group. The discovery of low intensity changes may require significantly higher animal numbers.

Clinical implications of SELDI-MS for diagnosis and prognosis of heart diseases. Despite these limitations, there is currently no other proteomic method that allows a similarly efficient high-throughput generation of cardiac protein profiles using such a small sample size. Therefore, SELDI-MS may become a useful complementary technique for the diagnosis and prognosis of cardiac diseases. For instance, this technique may permit a fast characterisation of biopsy material taken from the diseased hearts of patients. As shown in Figs. 4 and 5 for control and MI rat hearts, even a simple comparison of two peak intensities resulted in a correct diagnosis in nearly $80 \%$ of all hearts investigated. A consideration of further peak alterations in combination with data evaluation by bio-informatic tools may yield valuable diagnostic or even prognostic parameters in the future. Moreover, meaningful protein profiles or markers of heart failure might be also discovered in serum samples from patients with heart disease. Finally, we suggest that the rat infarct model in combination with SELDI-MS should allow a high-throughput testing of drugs for therapeutic approaches or even a temporal protein profiling leading to the identification of novel biomarkers of acute myocardial infarction.

\section{Acknowledgements}

The authors would like to thank Professor Benndorf for carefully reading the manuscript, and Karin Schoknecht, Sandra Bernhardt, and Annett Bleul for their excellent technical assistance. This work was supported by a grant of the German Federal Ministry of Education and Research (BMBF) and the Interdisciplinary Center for Clinical Research (ICCR) Jena to F.v.E., and by a BMBF grant no. 01ZZ0105, ICCR Jena (projects 4.10 and 4.12) to R.S. and T.Z.

\section{References}

1. Levy D, Kenchaiah S, Larson MG, Benjamin EJ, Kupka MJ, Ho KK, Murabito JM and Vasan RS: Long-term trends in the incidence of and survival with heart failure. N Engl J Med 347: 1397-1402, 2002.

2. Ho KK, Pinsky JL, Kannel WB and Levy D: The epidemiology of heart failure: The Framingham Study. J Am Coll Cardiol 22: 6A-13A, 1993.

3. Pfeffer MA and Braunwald E: Ventricular remodelling after myocardial infarction. Experimental observations and clinical implications. Circulation 81: 1161-1172, 1990.

4. Myerburg RJ and Castellanos A: Cardiac arrest and sudden cardiac death. In: Heart Disease: A Text Book of Cardiovascular Medicine. Braunwald E (ed). W.B. Saunders Co., Philadelphia, pp742-779, 1997.

5. Ferrans VJ: Morphology of the heart in hypertrophy. Hosp Pract (Off Ed) 18: 67-78, 1983 .

6. Dalen H, Odegarden S and Saetersdal T: The application of various electron microscopic techniques for ultrastructural characterization of the human papillary heart muscle cell in biopsy material. Virchows Arch A Pathol Anat Histopathol 410: 265-279, 1987.

7. Heinke MY, Wheeler CH, Yan JX, Amin V, Chang D, Einstein R, Dunn MJ and dos Remedios CG: Changes in myocardial protein expression in pacing-induced canine heart failure. Electrophoresis 20: 2086-2093, 1999.

8. Kang PM and Izumo S: Apoptosis and heart failure: A critical review of the literature. Circ Res 86: 1107-1113, 2000.

9. Jiang L, Tsubakihara M, Heinke MY, Yao M, Dunn MJ, Phillips W, dos Remedios CG and Nosworthy NJ: Heart failure and apoptosis: electrophoretic methods support data from micro- and macro-arrays. A critical review of genomics and proteomics. Proteomics 1: 1481-1488, 2001.

10. Van Eyk JE: Proteomics: unraveling the complexity of heart disease and striving to change cardiology. Curr Opin Mol Ther 3: 546-553, 2001 .

11. Hwang JJ, Allen PD, Tseng GC, Lam CW, Fananapazir L, Dzau VJ and Liew CC: Microarray gene expression profiles in dilated and hypertrophic cardiomyopathic end-stage heart failure. Physiol Genomics 10: 31-44, 2002.

12. Dos Remedios CG, Liew CC, Allen PD, Winslow RL, Van Eyk JE and Dunn MJ: Genomics, proteomics and bioinformatics of human heart failure. J Muscle Res Cell Motil 24: 251-260, 2003.

13. Chugh SS, Whitesel S, Turner M, Roberts CT Jr and Nagalla SR: Genetic basis for chamber-specific ventricular phenotypes in the rat infarct model. Cardiovasc Res 57: 477-485, 2003.

14. McGregor E and Dunn MJ: Proteomics of heart disease. Hum Mol Genet 12: R135-R144, 2003.

15. Bukowska A, Lendeckel U, Kahne T and Goette A: Proteomics in myocardial diseases. Pathol Res Pract 200: 135-145, 2004.

16. Vivanco F, Martin-Ventura JL, Duran MC, Barderas MG, Blanco-Colio L, Darde VM, Mas S, Meilhac O, Michel JB, Tunon J and Egido J: Quest for novel cardiovascular biomarkers by proteomic analysis. J Proteome Res 4: 1181-1191, 2005.

17. Ellinghaus P, Scheubel RJ, Dobrev D, Ravens U, Holtz J, Huetter J, Nielsch U and Morawietz H: Comparing the global mRNA expression profile of human atrial and ventricular myocardium with high-density oligonucleotide arrays. J Thorac Cardiovasc Surg 129: 1383-1390, 2005.

18. Anderson NL and Anderson NG: Proteome and proteomics: new technologies, new concepts, and new words. Electrophoresis 19: 1853-1861, 1998.

19. Gygi SP, Rochon Y, Franza BR and Aebersold R: Correlation between protein and mRNA abundance in yeast. Mol Cell Biol 19: $1720-1730,1999$.

20. Tang N, Tornatore P and Weinberger SR: Current developments in SELDI affinity technology. Mass Spec Rev 23: 34-44, 2004.

21. Roesch Ely M, Nees M, Karsai S, Magele I, Bogumil R, Vorderwulbecke S, Ruess A, Dietz A, Schnolzer M and Bosch FX: Transcript and proteome analysis reveals reduced expression of calgranulins in head and neck squamous cell carcinoma. Eur J Cell Biol 84: 431-444, 2005.

22. Seibert V, Wiesner A, Buschmann T and Meuer J: Surfaceenhanced laser desorption ionization time-of-flight mass spectrometry (SELDI TOF-MS) and ProteinChip technology in proteomics research. Pathol Res Pract 200: 83-94, 2004. 
23. Patel KP, Zhang PL and Carmines PK: Neural influences on renal responses to acute volume expansion in rats with heart failure. Am J Physiol 271: H1441-H1448, 1996.

24. Benndorf K: Multiple levels of native cardiac $\mathrm{Na}^{+}$channels at elevated temperature measured with high-bandwidth/low-noise patch clamp. Pflügers Arch 422: 506-515, 1993.

25. Melle C, Ernst G, Schimmel B, Bleul A, Koscielny S, Wiesner A, Bogumil R, Moller U, Osterloh D, Halbhuber KJ and von Eggeling F: Biomarker discovery and identification in laser microdissected head and neck squamous cell carcinoma with ProteinChip ${ }^{\circledR}$ technology, two-dimensional gel electrophoresis, tandem mass spectrometry, and immunohistochemistry. Mol Cell Proteomics 2: 443-452, 2003.

26. Anand IS, Liu D, Chugh SS, Prahash AJ, Gupta S, John R, Popescu F and Chandrashekhar Y: Isolated myocyte contractile function is normal in postinfarct remodeled rat heart with systolic dysfunction. Circulation 96: 3974-3984, 1997.
27. Rozanski GJ, Xu Z, Zhang K and Patel KP: Altered $\mathrm{K}^{+}$current of ventricular myocytes in rats with chronic myocardial infarction. Am J Physiol 274: H259-H265, 1998.

28. Ungerer M, Bohm M, Elce JS, Erdmann E and Lohse MJ: Altered expression of beta-adrenergic receptor kinase and beta 1-adrenergic receptors in the failing human heart. Circulation 87: 454-463, 1993.

29. Lorenz K, Lohse MJ and Quitterer U: Protein kinase C switches the Raf kinase inhibitor from Raf-1 to GRK-2. Nature 426: 574-579, 2003. 